\title{
DETECTION OF COMPLEX TERRAIN-INDUCED WIND SHEAR BY DOPPLER LIDAR AT BEIJING CAPITAL INTERNATIONAL AIRPORT
}

\author{
Xiaoying Liu' ${ }^{*}$, Songhua $\mathrm{Wu}^{1,2}$, Hongwei Zhang ${ }^{1}$, Jianjun Zhang ${ }^{3}$, Zhiqiang $\mathrm{He}^{3}$, Xi Zhang ${ }^{3}$ \\ ${ }^{1}$ Ocean Remote Sensing Institute, College of Information Science and Engineering, \\ Ocean University of China, Qingdao 266100, China. \\ ${ }^{2}$ Laboratory for Regional Oceanography and Numerical Modeling, Pilot National Laboratory for Marine \\ Science and Technology (Qingdao), Qingdao 266237, China. \\ ${ }^{3}$ North China Regional Air Traffic Management Bureau of CAAC, Beijing 100621, China. \\ *Email:lxy6302@stu.ouc.edu.cn
}

\begin{abstract}
In November 2018, the lidar-based wind shear synchronous experiment was performed at Beijing Capital International Airport (BCIA). In this experiment, aiming at the measurement of the terrain-induced wind shear and the wind field around the runway, the glide path scanning mode, and the RHI strategy were conducted alternately. Radial velocity retrieved from the glide path scanning can obviously present the wakes caused by complex terrain (e.g., hills, tall trees, residential and terminal buildings). The Pulse Coherent Doppler Lidar (PCDL) warned the terrain-induced wind shear, which was verified by the pilot report. The wind field structure around the runway under the wake effect and the building shielding effect is also analyzed.
\end{abstract}

\section{INTRODUCTION}

Wind shear has a great threat to aviation safety according to statistical reports ${ }^{[1]}$. Wind speed or wind direction changes rapidly during wind shear, which alters the lift of aircraft and causes deviations from the predetermined flight path. On account of the limitations of conventional wind shear detection instruments (such as anemometer networks, weather radars, and wind profilers), lidar has gradually become the popular technology to observe and alert wind shear, with its high spatial-temporal resolutions and flexible scanning modes [2]. Hong Kong International Airport (HKIA), which is often plagued by wind shear due to its special geographical location, introduced lidar to the airport for the first time for routine observations throughout the day and developed an alerting system for extensive researches ${ }^{[2-3]}$.

Recently, wind shear studying has made great progress based on lidars in the design of effective wind shear scanning strategies ${ }^{[4-7]}$ and the accuracy of alerting methods ${ }^{[8-10]}$. And the distribution law of wind shear has been further explored through wind shear statistical characteristics and turbulence feature analysis along the glide path ${ }^{[7-8,11-12]}$. Wind shear can occur in a wide range of weather conditions, like terrain effects under stably stratified boundary layer, sea breeze with sunshine, and gust or microburst in severe convection weather. The terrain-induced wind shear becomes difficult for warning due to its high spatial and temporal variability wind field, which plays a dominant role in many factors with accounting for $70 \%$ in HKIA [2].

This paper explores the complex terrain-induced wind shear by using Pulse Coherent Doppler Lidar (PCDL) and the wind field structure around the runway under the wake effect and the building shielding effect at Beijing Capital International Airport (BCIA).

\section{LIDAR EXPERIMENT AND METHODOLOGY}

As the largest passenger throughput airport in China, BCIA is located in the center of Beijing. Although there are no high mountains around it, the presence of hills, trees, and buildings makes the wind field more complicated. The weather conditions in Beijing are controlled by a typical monsoon climate. Therefore, the northerly wind and northwesterly wind become prevailing in the winter and early springtime at BCIA, accompanied by more frequent windy weather.

BCIA contains three runways, namely $36 \mathrm{~L} / 18 \mathrm{R}$, 36R/18L and 01/19, as shown in Fig.1. Statistics data reported by the pilots (from 2015, 2016 and 2018) showed that the wind shear mainly occurred 


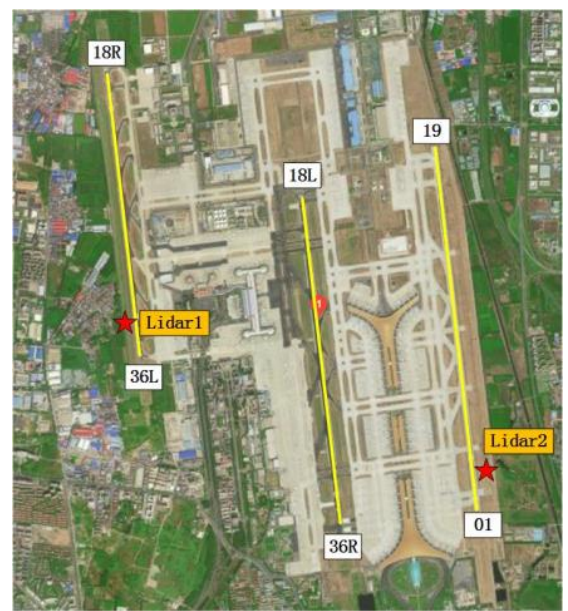

Fig.1. The geographical environment of BCIA.

in the 36L and 01 runway at BCIA, accounting for $43 \%$ and $31 \%$ respectively, as shown in Fig.2. Subsequently, the wind direction when the pilots reported the occurrence of wind shear in 36L and 01 runway corridor (from 2018) was analyzed in Fig.3, and the results reveal that the northwester, norther, and wester prevailed. In consideration of the geographical environment around BCIA, complex terrains under the above-mentioned prevailing wind should be responsible for this. The residential buildings, tall trees and small mounds on the west of 36L/18R runway and the terminal buildings which are adjacent west side to 01/19 will cause disturbance to the wind field along the glide path in $36 \mathrm{~L}$ and 01.

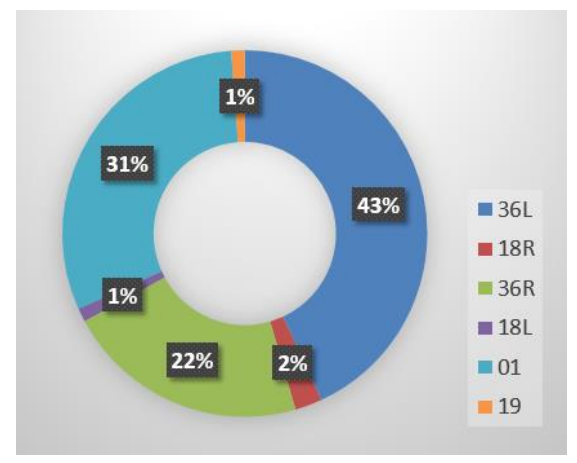

Fig.2. Wind Shear statistics reported by the pilots in different runways at BCIA (from 2015, 2016 and 2018).

Lidar has an advantage in exploring the complex terrain-induced wind shear with a rapid change of wind field in the clear sky. Since January 2018, BCIA has introduced two lidars located at $36 \mathrm{~L}$ (Lidar1) and 18R (Lidar 2) runway for scientific

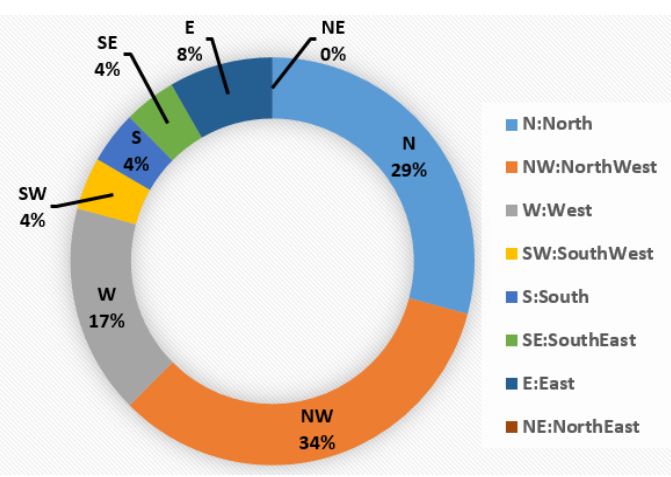

Fig.3. Wind direction statistics during wind shear at $36 \mathrm{~L}$ and 01 runway corridor at BCIA (from 2018).

research. With the arrival of the winter monsoon, in November 2018, Lidar2 moved to 01 runway (as shown in Fig.1) to observe the terrain-induced wind shear under prevailing wind. During the experiment, Lidar1 and Lidar2 both adopted the glide path scanning strategies [2, 4] with the coordinate change of azimuth and pitch angles to carry out the synchronous observation. Table 1 lists the detailed specifications of the PCDL. In the experiment, the distance between the two lidar locations and the centerline of $36 \mathrm{~L}$ and 01 runway are all $70 \mathrm{~m}$, so that the velocity along the laser beam can be as nearly equal to the real velocity along the glide path. And then, the radial velocities of lidars were used to construct the headwind profiles experienced by the aircraft along the glide path.

Table 1. Specifications of the PCDL system at BCIA.

\begin{tabular}{cc}
\hline Parameters & Specification \\
\hline Radial Spatial Resolution & $30 \mathrm{~m}$ \\
Measurement Range* & 60 to $4000 \mathrm{~m}$ \\
Wavelength & $1.5 \mu \mathrm{m}$ \\
Pulse Energy & $150 \mu \mathrm{J}$ \\
Pulse Repetition Frequency & $10 \mathrm{kHz}$ \\
Scanner Positioning Accuracy & $0.1^{\circ}$ \\
Resolution of Velocity & $0.1 \mathrm{~m} / \mathrm{s}$ \\
\hline
\end{tabular}

* Weather condition related

\section{RESULTS}

\subsection{Complex terrain wakes and wind shear}

In December each year, northerly and northwest winds are prevalent at BCIA. The runway corridor 01 and $36 \mathrm{~L}$ are located downwind of complex terrain (as shown in Fig.1), which is susceptible to 
the wakes of the hills (or tall trees) and buildings. Fig.4 shows the obvious influence of wakes formed by the terminal under prevailing wind in 01 runway. The wind strips will disturb the velocity along the glide path and increase the bumpiness of the aircraft with potential hazards. The pilot reported the presence of wind shear in 01 runway at 19:03 (local time) on December 27, 2018, at this time, the background wind field is shown in the right half of Fig.4. Meanwhile, the PCDL also issued a wind shear alert, as illustrates in Fig.5. The velocity dropped from $17.7 \mathrm{~m} / \mathrm{s}$ to $8.9 \mathrm{~m} / \mathrm{s}$ during landing from far afield to the touchdown points, with changing about $8.8 \mathrm{~m} / \mathrm{s}$ (17kt) which is much more than $7.7 \mathrm{~m} / \mathrm{s}$ (15kt) adopted by the International Civil Aviation Organization (ICAO).
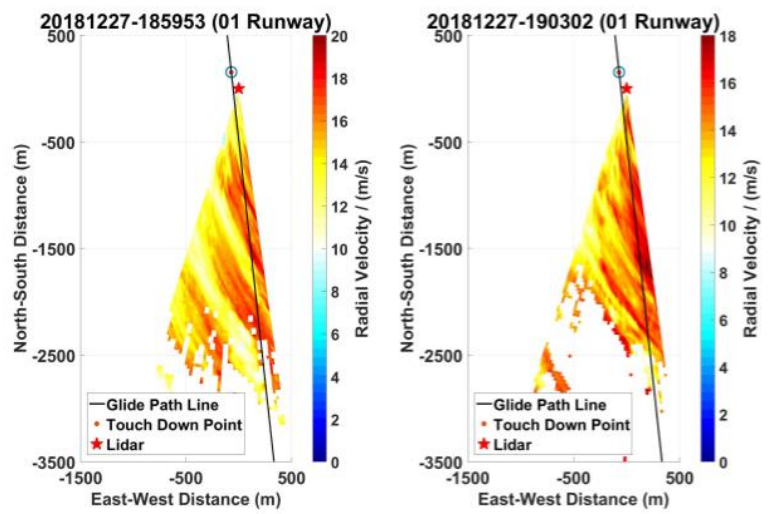

Fig.4. Glide path radial velocity of 01 runway on December 27, 2018.

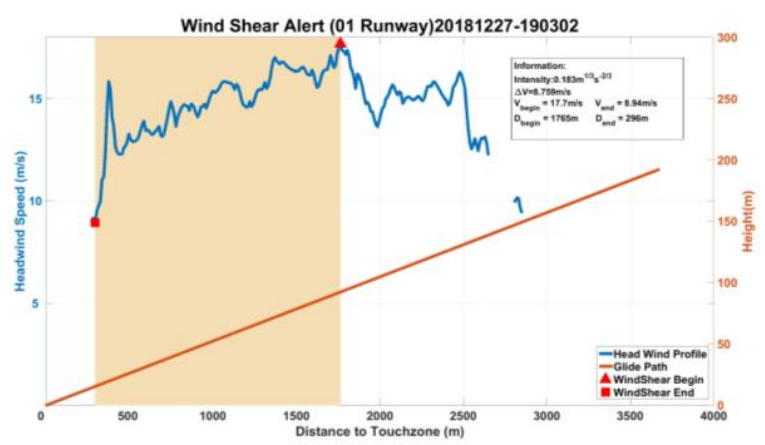

Fig.5. Headwind profile of 01 runway on December 27, 2018.

During this period, under the influence of strong northwest wind, the velocity in the 36L runway was affected by the wakes of tall trees, hills, and residential buildings, as the stripes formed in Fig.6. Lidar also issued a wind shear signal that the difference of velocity was up to $10.6 \mathrm{~m} / \mathrm{s}(20 \mathrm{kt})$ which depicted the situation is more serious than 01 runway at the same time (If the time difference is less than $1.5 \mathrm{~min}$, it is considered to be synchronous between $36 \mathrm{~L}$ and 01 runways in this paper.) as shown in Fig.5 and Fig.7. In addition to the wake effect, the smaller velocity at the lower altitude (the blue area near the lidar, as shown in Fig.6) should contribute to this serious situation. Fig.7 presents that the higher-altitude velocity was maintained above $15 \mathrm{~m} / \mathrm{s}$, thus forming a sharp velocity change along the glide path.
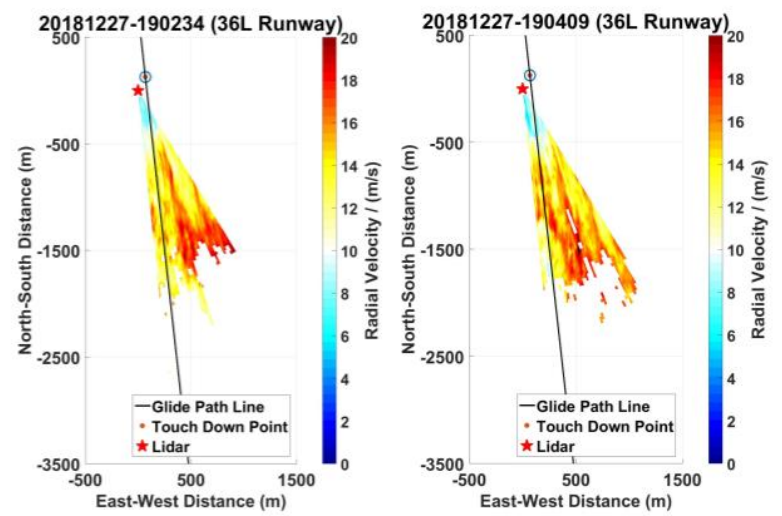

Fig.6. Glide path radial velocity of $36 \mathrm{~L}$ runway on December 27, 2018.

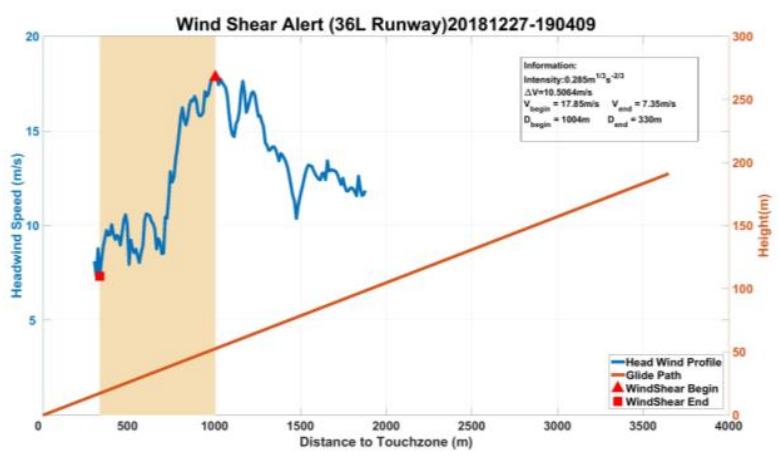

Fig.7. Headwind profile of $36 \mathrm{~L}$ runway on December 27, 2018.

\subsection{Complex topography and wind field along the runway}

In this experiment, the RHI scanning strategy and the glide path scanning mode were designed alternately. For the RHI scanning, the azimuth of PCDL was consistent with the 01/19 runway's azimuth, and the pitch angle varied between 0 and 45 degrees. Wind shear alerts were issued by the PCDL at 03:40 and 03:47 (local time) on January 04, 2019, respectively. The glide path radial velocity figures showed evident stripes that are 
the terminal building wakes, which was not shown in this paper. Fig. 8 shows the radial velocity retrieved by RHI scanning for the above time period. In this graph, with zero representing the location of PCDL, the positive distances represent the positions at the south of lidar along the runway and vice versa for the northern positions. In the upper graph of the Fig.8, there are two lower-velocity zones in the wind field below the height of $100 \mathrm{~m}$ at $600 \mathrm{~m}$ and $1700 \mathrm{~m}$ account of wake effect. And the flight glide path just passed through the two zones, which were accompanied by the wind shear or turbulence. In the lower part of Fig.8, a wind area of lower-velocity was distributed at the distance of $60 \mathrm{~m}$ to $1600 \mathrm{~m}$ below the altitude of $200 \mathrm{~m}$, mainly because this area is located on the east side of the terminal building (referring to Fig.1) with strong shielding effect.

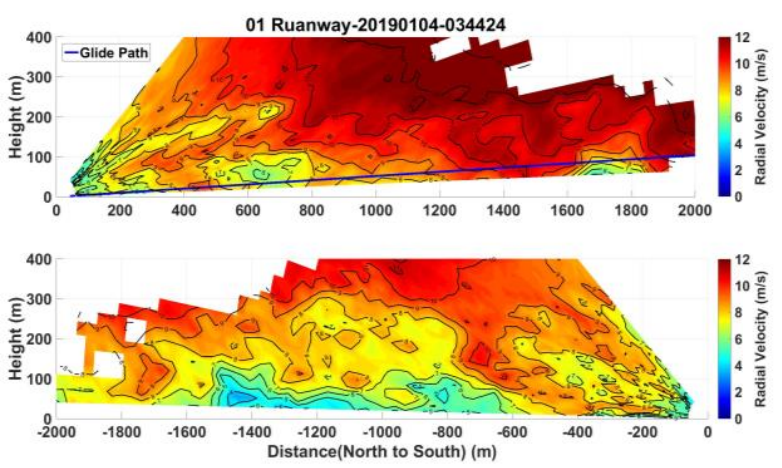

Fig.8. Radial velocity from RHI scanning around the $01 / 19$ runway.

\section{CONCLUSIONS}

Glide path mode designed to detect the wind shear and RHI scanning strategy used to explore the wind field around the runway observed alternately in this synchronous experiment between $36 \mathrm{~L}$ runway and 01 runway. The stripes appearing in the glide path scanning radial velocity indicate the wake effects produced by complex terrain. The PCDL warned the terrain-induced wind shear, and which was verified by the pilot report. The results show that the difference between higher-velocity and lower-velocity at different altitudes in $36 \mathrm{~L}$ runway exacerbates the variation of the headwind profile and brings a more severe wind shear situation. The structure around the runway can be obtained by RHI scanning. The complex terrain wake will form lower-velocity areas along the glide path, which will bring the wind shear and turbulence. In addition, under the shielding effect of the terminal building, a wide range of lowervelocity was formed at low altitudes.

\section{ACKNOWLEDGEMENTS}

This work was supported by the National Key Research and Development Program of China, grant number 2016YFC1400904 and North China Regional Air Traffic Management Bureau of CAAC. We thank our colleagues including Xiaoye Wang and Xiaomin Chen from Ocean University of China for preparing and conducting the experiment.

\section{REFERENCES}

[1] Hallowell, R.G., et al. Lincoln Laboratory Journal 18 (2) (2010)

[2] Shun, C. M., et al. Journal of Atmospheric and Oceanic Technology 25(5): 637-655 (2008)

[3] Shun, C M, et al. 10th Conference on Aviation, Range, and Aerospace Meteorology (2002)

[4] Zhang, H, et al. 19th Coherent Laser Radar Conference (2018)

[5] CHAN, P. W., et al. 12th Conference on Aviation, Range, and Aerospace Meteorology (2006)

[6] Chan, P. W, et al. Journal of Atmospheric and Oceanic Technology 29(2): 207-220 (2012)

[7] Zhang, H, et al. Infrared Physics \& Technology 96:113-122 (2019)

[8] Chan, P. W, et al. Meteorologische Zeitschrift, 20(6): 661-670 (2011)

[9] Chan, P. W. Meteorologische Zeitschrift 21(2): 193-204 (2012)

[10] Lee, Y. F, et al. Meteorological Applications 21(1): 86-93 (2014)

[11] Chan, P. W. 12th Conference on Aviation, Range, and Aerospace Meteorology (2006)

[12] Chan, P W. Meteorologische Zeitschrift 19(6): 549-563 (2010) 